\title{
On the Use of Godhavn H-Component as an Indicator of the Interplanetary Sector Polarity
}

by

Leif Svalgaard

October 1974

Reproduction in whole or in part
is permitted for any purpose of is permitted for any purpose of
the United States Government.

(NASA-CR-140858) ON THE USE OF GODHAVN

SUIPR Report No. 596 H-COMPONENT AS AN INDICATOR OF THE INTERPLANETAEY SECTOR POLARITT (Stanford Univ.) 26 p HC $\$ 3.75$ CSCL 03B CSCL $03 B$ Unclas N75-12867 02879 G3 3 Contract N00014-67-A-0112-0068 National Aeronautics and Space Administration Grant NGR 05-020-559 and National Science Foundation Grant GA-31138 
UNCLASS IFIED

SECURITY CLASSIFICATION OF THIS PAGE (When Data Entered)

\begin{tabular}{|c|c|}
\hline REPORT DOCUMENTATION PAGE & $\begin{array}{l}\text { READ INSTRUCTIONS } \\
\text { BEFORE COMPLETING FORM }\end{array}$ \\
\hline \begin{tabular}{l|l} 
1. REPORT NUMBER & 2. GOVT ACCESSION NO. \\
SUIPR Report No. 596 & \\
\end{tabular} & 3. RECIPIENT'S CATALOG NUMBER \\
\hline $\begin{array}{l}\text { 4. TITLE \{and Subritie\} } \\
\text { ON THE USE OF GODHAVN H-COMPONENT AS AN } \\
\text { INDICATOR OF THE INTERPLANETARY SECTOR POLAR ITY }\end{array}$ & $\begin{array}{l}\text { 5. TYPE OF REPORT \& PERIOD COVERED } \\
\text { Scientific Technica } 1\end{array}$ \\
\hline$\cdot$ & 6. PERFORMING ORG. REPORT NUMBER \\
\hline $\begin{array}{l}\text { 7. AUTHOR(s) } \\
\text { Leif Svalgaard }\end{array}$ & $\begin{array}{l}\text { 8. CONTRACT OR GRANT NUMBER(s) } \\
\text { N00014-67-A-0112-0068 }\end{array}$ \\
\hline $\begin{array}{l}\text { 9. PERFORMING ORGANIZATION NAME AND ADORESS } \\
\text { Institute for Plasma Research } \\
\text { Stanford University } \\
\text { Stanford, California } 94305\end{array}$ & $\begin{array}{l}\text { 10. PROGRAM ELEMENT, PROJECT, TASK } \\
\text { AREA \& WORK UNIT NUMBERS }\end{array}$ \\
\hline 11. CONTROLLING OFFICE NAME AND ADDAESS & \begin{tabular}{c|c} 
12. REPORT DATE & 13. NO. OF PAGES \\
October 1974 & 24
\end{tabular} \\
\hline $\begin{array}{l}\text { Phil Surra, Office of Naval Research } \\
\text { Durand 165, Stanford University } \\
\text { Stanford, California } 94305\end{array}$ & $\begin{array}{l}\text { 15. SECURITY CLASS. (of this report) } \\
\text { UNCLASSIFIED }\end{array}$ \\
\hline 14. MONITORING AGENCY NAME \& ADDRESS (if diff. from Controlling Office) & \\
\hline & $\begin{array}{l}\text { 15a. DECLASSIFICATION/DOWNGRADING } \\
\text { SCHEDULE }\end{array}$ \\
\hline
\end{tabular}

16: OISTRIBUTION STATEMENT (of this report)

This document has been approved for public release and sale; 1 ts distribution is unlimited.

17. DISTRIBUTION STATEMENT (of the abstract entered in Block 20, if different from report)

18. SUPPLEMENTARY NOTES

TECH ; OTHER

19. KEY WORDS (Continue on reverse side if necessary and identify by block number)

Sector structure

Geomagnetic index

20. ABSTRACT (Continue on reverse side if necessary and identify by block number)

An objective method of inferring the polarity of the interplanetary magnetic field using the H-component at Godhavn is presented. The objectively inferred polarities are compared with a subjective index inferred earlier (Svalgaard, 1972b). It is concluded that no significant difference exists between the two methods. The inferred polarities derived from Godhavn $H$ is biased by the $\mathrm{s}_{\mathrm{q}}^{\mathrm{p}}$ signature in the sense that during the summer prolonged intervals of geomagnetic calm will result in inferred Away polarity regardless of the actual sector polarity. This bias does not signiflcantly alter the largescale structure of the inferred sector structure. 
ON THE USE OF GODHAVN H-COMPONENT AS AN INDICATOR OF

THE INTERPLANETARY SECTOR POLARITY

by

Leif Svalgaard

Office of Naval Research

Contract N00014-67-A-0112-0068

National Aeronautics and Space Administration

Grant NGR 05-020-559

and

National Science Foundation

Grant GA-31138

SUIPR Report No, 596

October 1974

Institute for Plasma Research

Stanford University

stanford, California

Submitted to Journal of Geophysical Research 
ON THE USE OF GODHA VN H-COMPONENT AS AN INDICATOR OF

THE INTERPLANETARY SECTOR POLARITY

\author{
Leif Svalgaard \\ Institute for Plasma Research \\ Stanford University \\ Stanford, California 94305
}

\begin{abstract}
An objective method of inferring the polarity of the interplanetary magnetic field using the H-component at Godhavn is presented. The objectively inferred polarities are compared with a subjective index inferred earlier (Svalgaard, 1972b). It is concluded that no significant difference exists between the two methods. The inferred polarities derived from Godhavn $H$ is blased by the $S_{q}^{p}$ signature in the sense that during summer prolonged intervals of geomagnetic calm will result in inferred Away polarity regardless of the actual sector polarity. This bias does not significantly alter the large-scale structure of the inferred sector structure.
\end{abstract}


ON THE USE OF GODHAVN H-COMPONENT AS AN INDICATOR OF

THE INTERPLANETARY SECTOR POLARITY

\author{
Leif Svalgaard \\ Institute for Plasma Research, Stanford University \\ Stanford, California 94305
}

Fougere and Russell (1974) suggest that evaluation of the accuracy of the inferred interplanetary sector polarity (Svalgaard, 1972a) is difficult due to the subjective nature of the inferred index and further due to the apparent lack of a detailed recipe on how to infer the sector polarity from polar cap magnetograms. It is the purpose of the present note to provide one such recipe, and also to show that the quality of the published list of inferred polarities going back to 1926 (Svalgaard, 1972b) is not seriously affected by the fact that for most years before 1964 only one station (Godhavn, $77 .{ }^{\circ} 5$ invariant latitude) was used in deriving the list.

The above statements should be qualified by noting that the recipe which will be presented certainly is not the perfect recipe, but it has the virtue of belonging to a class of recipes which are very simple yet still useful. Furthermore, the extent to which the inferred index (the so-called $\mathrm{A} / \mathrm{C}$ index) is useful depends somewhat on the purpose of the analysis. Just as the $\mathrm{Kp}$ index does not give meaningful results when used for deriving the diurnal variation of geomagnetic activity, there may well be (and apparently are (Fougere, 1974)) limitations inherent in the present $\mathrm{A} / \mathrm{C}$ index, which may preclude its application to certain problems without affecting its usefulness in other areas.

In the original $A / C$ classification, a day was classified as type $C$ (associated with Toward sector polarity) if the Z-magnetograms from nearpolar stations show a broad positive perturbation around local noon; a negative perturbation would classify the day as of type A (associated with Away polarity). It was found that the amplitude of these perturbations of the vertical component $\mathrm{Z}$ decreased with increasing distance from the invariant poles. Instead, perturbations are found in the horizontal component $\mathrm{H}$. The sense of the H-perturbations is opposite, of the sense of the near-pole $\mathrm{Z}$-perturbations. Figure 1 shows the average diurnal variation of the $\mathrm{H}-$ 
component at Godhavn for 1950. The curves labelled $A$ and $C$ are the average variations during days classified by svalgaard (1972b) as being of type A and of the type $C$, respectively. The all-day average variation is also shown in the figure. A six-hour interval around $18^{\mathrm{h}} \mathrm{UT}$ is delineated by two stippled lines. In this interval, the largest differences between the $A-$ and the $\mathrm{C}-$ type variation occurs.

If a Godhavn H-magnetogram for a given day shows a definite local maximum within the interval $15^{\mathrm{h}}-21^{\mathrm{h}} \mathrm{UT}$, the day is classified as type $\mathrm{A}$, while a definite local minimum or depression will classify the day as type $C$. This recipe leaves room for a type $B$, when the variation is irregular during the interval of interest. It turns out that type $B$ occurs rarely enough $\approx 15 \%$ of the time) to make the A/C type classification meaningful. Originally a choice was made such that every day was classified only in terms of $A$ or c.

The local maxima and minima (or enhancements and depressions) used to determine the type of the daily variation appear, to be superposed on the normal diurnal variation, which is roughly sinusoidal. The amplitude of this background curve varies greatly with season and with disturbance level. To a certain degree, the quality of the $\mathrm{A} / \mathrm{C}$ index is then dependent upon how well the background can be discerned and removed. This in turn demands some familiarity with the Godhavn magnetograms. The situation is analogous to the problem of determining Bartels' K-index. This index is basically a subjective index, because its determination requires recognition and subsequent removal of the normal, undisturbed diurnal Sq variation, which itself varies from day to day or even may change character during the day. In case of an isolated K-disturbance, the background reference level can normally be interpolated on the magnetogram using the quieter intervals before and after the disturbance. Similar consideration apply for the determination of the A/C index; andjust as for the K-index, the difficulty in removing the background has the largest influence when scaling small disturbances.

A simple approach to the problem of removing the background level is as follows: In Figure 2, data for May 1968 is plotted such that during the interval $15^{\mathrm{h}}-21^{\mathrm{h}} \mathrm{UT}$ the actual variation of the horizontal component at Godhavn is shown for each day, while for all other times simply the monthly mean value of $\mathrm{H}$ is shown. The figure is then composed of a straight line interrupted each day by the (very time-compressed) actual $\mathrm{H}$-trace. If $\mathrm{H}$ has a local enhance- 
ment within the interval of interest $\left(15^{\mathrm{h}}-2 I^{h_{U T}}\right)$, a positive spike will result for that day on Figure 2, while a depression will show as a negative spike. Figure 2 just displaysa series of such spikes. The sector polarity as measured by spacecraft (Wilcox and Colburn, 1970) is indicated for each day on Figure 2 with a + (Away) or a - (Toward) placed near the spike for that day. Generally we see the familiar pattern, that a positive spike is associated with Away polarity and a negative spike is associated with Toward polarity. In a few cases a mixed signature is seen, but the data in Figure 2, as well as simila $x$ plots for other months of 1968 is in good accordance with the result of Friis-Christensen et al. (1971) that the A/C signature may be used to infer the sector polarity with a accuracy exceeding $85 \%$. Part of the remaining uncertainity is related to the observation (Frits-Christensen et al. (1972)) that the sign of the azimuthal component of the interplanetary magnetic field rather than its polarity seems to determine the sign of the A/C perturbation.

The apparent success of the very simple procedure used in preparing Figure 2 in producing features (spikes) which correlate well with the interplanetary sector polarities as measued by spacecraft suggests the following formal recipe for assigning a character (A, $B$, or $C$ ) to a UT day characterizing the inferred IMF polarity.

1. Use the horizontal component, $H$, at Godhavn.

2. For each day within a given month, subtract the monthly mean value of $\mathrm{H}$ from the hourly means of $\mathrm{H}$.

3. Set the reduced values of $\mathrm{H}$ equal to zero for all hours outside the interval $15^{\mathrm{h}}-22^{\mathrm{h}}$ UT, thus simulating the baseline on Figure 2.

4. Determine the maximum value, $\mathrm{HA}$, and the minimum value, $\mathrm{HC}$, for each day. Due to the previous step we will generally have that $\mathrm{HA} \geq 0$ and $\mathrm{HC} \leq 0$.

5. If $\mathrm{HA}>-\mathrm{HC} / 2$ then classify the day as type $\mathrm{A}$, else if $\mathrm{HC}<-\mathrm{HA} / 2$ then classify the day as type $C$, else classify the day as type $B$. Using this recipe, the $\mathrm{A} / \mathrm{C}$ index has been redeterimined for an interval in 1968 and compared with spacecraft measurements of the interplanetary magnetic field polarity. The result is shown in Figure 3 . Even with this very crude recipe, which certainly is inferior to the visual judgement of the experienced observer, we obtain almost $80 \%$ agreement between the $\mathrm{A} / \mathrm{C}$ index and 
the sector polarity. The larger scale features of the sector structure are well defined by the $\mathrm{A} / \mathrm{C}$ index, and this seems to be the case independent of season. The point we are trying to make is that as long as we concentrate on the interval of the day where the A/C effects are largest, we obtain very reasonable agreement between the $\mathrm{A} / \mathrm{C}$ index and the sector polarity, even if the classification procedure is as rough as the one discussed above.

We shall not at this point discuss how much better one could do by using other stations at even higher latitudes such as Thule or Resolute Bay or by using more elaborate (and possibly more subjective or shrewd) techniques for removing the background level. Instead, we will note that by using only the Godhavn station and the simple recipe described above it seems possible to determine the large scalefeatures of the sector structure exhibited by the interplanetary magnetic field.

Figure 4 shows Godhavn $H$ plotted in the same format as in Figure 2, but for April 1950 when no spacecraft measurements of the interplanetary medium were available. Unless we assume that the response of the magnetosphere to the interplanetary magnetic field has changed between 1968 and 1950, we may again associate positive spikes with Away polarity and negative spikes with Toward polarity. Also shown in Figure 4 are the original visual estimates of the A/C index by Svalgaard (1972b). Generally we find that inferred Away polarity is dominant on days of type $A$, while inferred Toward polarity is predominant on days of type C as originally suggested by Svalgaard (1968). This correspondence is further evidenced by Figure 5 , where the original visual estimates are compared with the inferred polarities determined using the algorithm given above for each day of 1950. In all the cases we have examined here, the agreement between the various estimates and determinations is of the order $80 \%$ or better.

Having established that the $\mathrm{A} / \mathrm{C}$ index most of the time is well correlated with the polarity of the interplanetary magnetic field, the few cases with obvious disagreements command particular attention. If the disagreements depend systematically on other properties of the disturbance pattern, which is a very reasonable assumption, it may have a strong influence on some of the statistical properties of the $\mathrm{A} / \mathrm{C}$ index. Let us assume that the five international quiet days in a month always (for some reason) are classified as being of type A, while the five disturbed days always are classified as type $C$. The remaining twenty days are classified correctly. 
If geomagnetic activity were independent of the sector polarity, $2 \frac{1}{2}$ international quiet days and $2 \frac{1}{2}$ international disturbed days would be classified wrongly, meaning that out. of the 30-day month, 25 days were classified correctly corresponding to $83 \%$ agreement. We now assume that the quiet days have a $C_{i}$ character figure of 0 , the disturbed days a $C_{i}$ character figure of 2 , and that the remaining days are moderately active with a $C_{i}$ character figure of 1 . The average $C_{i}$ figure for type $A$ days then becomes $(10 * 1+$ $5 * 0) / 15=0.67$, while the average $C_{i}$ figure for type $C$ days becomes (10* $1+5 * 2) / 15=1.33$, or twice as high.

This idealized example shows that the A/C index well can have a high information content ( $83 \%$ agreement) yet be systematically contaminated such that $C$ days appear much more active than $A$ days. How serious this particular systematic error will be depends of course on to what research problem the A/C index is applied. One such application was the confirmation by Wilcox and Scherrer (1972) of a finding by Rosenberg and Coleman (1969), that the polarity of the interplanetary magnetic field measured out of the solar equatorial plane should be biased by the polarity of the magnetic pole of the sun that is on the same side of the equator as the interplanetary probe.

When the interplanetary sector structure was first discovered (Wilcox and Ness, 1965) during the decending phase of sunspot cycle \#19 there were four stable sectors. Analyses of the inferred field using the $\mathrm{A} / \mathrm{C}$ index (Svalgaard, 1973) show that this four-sector pattern is a persistent feature of at least the last five sunspot cycles. The main conclusion from the analysis of the $\mathrm{A} / \mathrm{C}$ index was that the solar sector structure evolves through rather similar patterns in each sunspot cycle. During most of the cycle a four sector structure with synodic recurrence period near 27 days is apparent. Near sunspot maximum there emerges a superposed structure having polarity into the sun with a width in longitude of about $100^{\circ}$ and a synodic recurrence period between 28 and 29 days. This "28 $\frac{1}{2}$ day feature" co-exists with the basic underlying four sectors for extended periods of time. It may at these times be difficult to discern the four-sector structure clearly, but when the $28 \frac{1}{2}$ day structure disappears or weakens some time after sunspot maximum, the four-sector structure becomes very prominent as the cycle progresses toward sunspot minimum. This evolutionary scheme has been observed directly by spacecraft during the present cycle and the $\mathrm{A} / \mathrm{C}$ index seems to indicate that the sunpot cycle variation of the sector structure is rather similar also in 
the previous four cycles.

If would seem that the $\mathrm{A} / \mathrm{C}$ index, even in its present form, can be used to study the large-scale evolution of the sector structure through the sunspot cycle. For other kinds of study, such as the average disturbance level for the two polarities separately, it seems equally certain that a revised $\mathrm{A} / \mathrm{C}$ index will be needed. A dilemma arises between conflicting views on how this index should be constructed. Should it be a homogeneous index derived from the Godhavn station only, but covering the full interval from 1926 to the present? Or should it be the "best possible" index in the sense that whenever additional stations are avallable, they should be utilized to improve the index? A case can be made for both points of view. The list published by Svalgaard $(1972 b)$ is not a homogeneous list because additional data from other polar cap stations (mostly Thule) was used when available (mostly after 1963).

Using published yearbooks from the Godhavn Geophysical Observatory and the recipe given above, a homogeneous $\mathrm{A} / \mathrm{C}$ index could be produced. Analysis of statistical properties of this index may show various differences between polarities, seasons or sunspot cycles. It would not be possible to establish which of these differences were due to artifacts in the index or due to real physical changes. A more constructive approach would be to intensify the study of polar cap geomagnetic variations, because it seems to the present author that a purely mechanical recipe based on a few initial observations is not the proper solution to the very important problem of Inferring the interplanetary magnetic field.

As Rostoker (1974) points out, the study of polar cap disturbances is still on unsure ground and large arrays of observatories need to be set up to allow researchers to separate out the magnetic effects of many contributing current systems. The observed magnetic perturbation pattern in the polar cap may stem from (1) the distant effect of the auroral electrojets, (2) the high-latitude Sq current flow, (3) cross polar cap ionosphere currents associated with magnetospheric convection, (4) the effects of distant fieldaligned currents penetrating the auroral oval and (5) the special vortexlike currents associated with variations in the azimuthal components of the interplanetary magnetic field. Varying degrees of activity produce dramatically different mixtures of all these effects, and much work remains to be done before those possible contributions can be separated out. A mechanical 
procedure which is not based on physical understanding can only provide a crude first approximation to the physical reality under study. But even an approximation can be very useful if applied within its limitations.

Returning to the discussion of interplanetary signatures in the geomagnetic field we shall study the reason why some quiet days appear to show the A-signature at Godhavn 1rrespective of the actual sign of the azimuthal component of the interplanetary field. Figure 6 shows the typical variation of Thule $\mathrm{Z}$ and Godhavn $\mathrm{H}$ for a few days around the sector boundary passing on July 25, 1968. These days are moderately to weakly disturbed. At Godhavn, we note the normal night maximum - indicated by $T$ on the Figure - and the morning mimimum - indicated by $S$. These features occur regularly every day independent of sector polarity. Both features invariably appear enhanced during magnetically active intervals. In addition, we note the characteristic signatures associated with the interplanetary field. A noon and afternoon positive perturbation indicated by A -correlated with Eastward-pointing interplanetary magnetic field, and the negative perturbation -indicated by $\mathrm{C}-$ associated with a Westward interplanetary field. The Thule records also show dramatic change of the diurnal variation as the sector boundary passes. We emphasize that the typical signatures are reversed at the two stations, maximum at one corresponds to mimimum at the other and visa versa.

However, this is not always the case. During intervals of prolonged geomagnetic calm, Thule $Z$ still shows the correct signature corresponding to the interplanetary field, while Godhavn $H$ develops a peculiar perturbation resembling very much the A-signature. This happens even if the interplanetary magnetic field is Westward - which should produce a C-signature. Figure 7 shows a good example of this phenomenon. During four consecutive days, the interplanetary magnetic field is steady Westward and geomagnetic activity is very low. Thule $z$ shows a clear C-signature on each day. All of what is left of a C-signature in Godhavn $\mathrm{H}$ is a minor depression around $2 \mathrm{I}^{\mathrm{h}}$ UT. Otherwise a positive perturbation - denoted with a $P$ on the records - in the afternoon is prominent in the diurnal variation. Without knowledge of the Thule magnetograms, these four days would be classified as being of type A because the P-perturbation has a strong resemblence with the A-signature. In fact, Figure 3 shows that these four days actually are classified as type $A$. What we are seeing here are examples of the $s_{q}^{p}$ variation, which may be observed on quiet days in the polar regions (e.g. Kawasaki and Akasofu (1973)). 
Figure 8 shows the average $s_{q}^{p}$ variation at Godhavn and it is now clear that many quiet days may have been classified as type A due to the similarity of the A-signature with the $s_{q}^{p}$ variation. With increasing activity the $p_{-}$ maximum in Figure 8 decreases and the S-minimum gets deeper which may cause the day to be classified as a type $c$. The $s_{q}^{p}$ variation thus introduces a bias, in the $A / C$ classification (when based on Godhavn $H$ ) in the sense that quiet days have a greater possibility of being classified as type $A$, while disturbed days have a greater possibility of being classified as type $C$. This systematic bias is expected to be most effective if the interplanetary signature is weak i.e. if the interplanetary magnetic field strength is small. Furthermore, the bias reflects the changing size of the polar cap. On an internationally quiet day the polar cap is small and Godhavn is heavily influenced by the $s_{q}^{p}$ currents flowing near the day-side polar cap boundary. With increasing activity the polar cap expands, and Godhavn becomes a true polar cap station situated well within the polar cap boundary and the influence of the $s_{q}^{p}$ currents is weaker. Since the size of the polar cap is determined by the North-South component of the interplanetary magnetic field (Akasofu et al, 1973) it seems reasonable to fit the observed values of $H$ to an expression of the form:

$$
\mathrm{H}=\mathrm{H}_{\mathrm{O}}+\mathrm{a} \cdot \mathrm{BY}+\mathrm{b} \cdot \mathrm{BZ}
$$

where $B Y$ and $B Z$ are the East-West and the North-South components of the interplanetary magnetic field, and $H_{0}$ is a slowly varyıng background field. It is well known that $H_{0}$ has a yearly variation of the order of $30 \%$. It is not known why. Furthermore, $\mathrm{H}_{\mathrm{O}}$ has a roughly sinusoidal daily variation of the order of $80 \%$. The coefficients $a$ and $b$ change during the day as shown in Figure 9, and also change with the seasons being larger during summer. The values plotted are averages of the twelve monthly values obtained by fitting (1) separately for each month of 1968. Figure 10 gives some indication of the kind of fit which may be obtained using the very simple expression (1). In computing the least-square fits hourly averages were used; due to the fact that on time-scales of an hour or more BY is genera11y greater then $B Z$ and because $a>b$ we see that the effects of BY are generally greater than those of $\mathrm{BZ}$ during the day-hours, while the opposite is true during the night-hours where a approaches zero. Roughly speaking then we might say that normally BY-related variations dominate during the day while BZ-related variations dominate during the night. The same conclusion was also reached by 
Kawasaki et a1, (1973).

Then, to the extent that fluctuations of $\mathrm{BZ}$ average out over a time scale of a few hours, Godhavn $H$ is a fair indicator of the East-West component of the interplanetary magnetic field. Only when BZ has constant sign for extended time intervals does its influences dominate over that of BY and systematic errors are introduced into an index of sector polarity based exclusively on Godhavn $H$. These systematic errors will have large importance in a study of the average disturbance properties of the two different polarities, but will be of minor or no importance in a study of the longterm evolution of the interplanetary sector structure.

\section{Acknowledgements}

This work was supported in part by the Office of Naval Research under Contract N00014-67-A-0112-0068, by the National Aeronautics and Space Administration under Grant NGR 05-020-559, and by the Atmospheric Sciences Section of the National Science Foundation under Grant GA-31l38. 


\section{References}

Akasofu, S.-I., P.D. Perreault, F. Yasuhara, and C.-I. Meng, Auroral substorms and the interplanetary magnetic field, J. Geophys. Res., 78 , $7490,1973$.

Fougere, P.F., Dependence of inferred magnetic sector structures upon geomagnetic and solar activity, Planet. Space Sci., in press, 1974.

Fougere, P.F. and C.T. Russe11, Comments on 'Interplanetary magnetic-sector structure, 1926-1971'. by L. Svalgaard and on 'Correspondence of solar field sector direction and polar cap geomagnetic field changes for 1965' by W.H. Campbell and S. Matsushita, J. Geophys. Res., in press, 1974.

FriismChristensen, E., K. Lassen, J.M. Wilcox, W. Gonzales, and D.S. Colburn, Interplanetary magnetic sector polarity from polar geomagnetic field observations, Nature Phys. Sci. , 234, 140, 1971.

Friis-Christensen, E., L. Lassen, J. Wilhjelm, J.M. Wilcox, W. Gonzales, and D.S. Colburn, Critical component of the interplanetary magnetic field responsible for large geomagnetic effects in the polar cap, J. Geophys. $\underline{\text { Res. }}$. 77, 3371,1972 .

Kawasaki, K. and S.-I. Akasofu, A possible current system associated with the $\mathrm{s}$ q variation, Planet. Space Sc1., 21, 329, 1973.

Kawasaki, K., F. Yasuhara and S.-I. Akasofu, Short-period interplanetary and polar magnetic field variations, Planet. Space Sci., 21, 1943, 1973. Rosenberg, R.L., and P.J. Coleman, Jr., Hellographic latitude dependence of the dominant polarity of the interplanetary magnetic field, J. Geophys. Res. , 74, 5611, 1969.

Rostoker, G., The geomagnetic field of external origin as observed at the Earth's surface, Trans. A.G. U., 55, 593, 1974.

Svalgaard, L., Sector structure of the interplanetary magnetic field and daily variation of the geomagnetic field at high latitudes, Danish Met. Inst. Geophys. Papers R-6, 11 pp., 1968.

Svalgaard, L., Interplanetary magnetic-sector structure 1926-1971, J. Geophys. Res., $77,4027,1972 \mathrm{a}$.

Svalgaard, L., Interplanetary magnetic sector structure 1926-1971, Danish Met. Inst. Geophys. Papers R-29, 34pp., 1972b. 
Svalgaard, L., Long-term stability of solar magnetic sector structure, Trans. A.G.U. , 54, 447, 1973.

Wilcox, J.M. and N.F. Ness, Quasi-stationary corotating structure in the interplanetary medium, J. Geophys. Res., 70, 5793, 1965.

Wilcox, J.M. and D.S, Colburn, Interplanetary sector structure near the maximum of the sunspot cycle, J. Geophys. Res., 75, 6366, 1970.

Wilcox, J.M. and P.H. Scherrer, Annual and solar-magnetic-cycle variations in the interplanetary magnetic field, 1926-1971, J. Geophys. Res., 77, 5385,1972 . 


\section{Figure Captions}

Fig. 1. Diurnal variation of the horizontal component at Godhavn during 1950. The curves labelled $A$ and $C$ are the average variations on days classified as being og type $A$ and of type $C$, respectively. In the interval delineated by stippled lines, the largest difference between the two types occurs.

Fig. 2. Data for May 1968 plotted such that during the interval $15^{\text {h }}-21^{\text {h }}$ UT the actual variation of the horizontal component at Godhavn is shown for each day, while for all other times the monthly mean value is shown as straight line segments. (see text)

Fig. 3. Comparison between the polarity of the interplanetary magnetic field (Toward the sun, or Away from the sun) as measured by spacecraft (Wilcox and Colburn, 1970) and the polarity inferred using the recipe described in the text. The data is displayed in 27-day Bartels' rotations, with the data of the starting day of each rotation shown at the left.

Fig. 4. Data for April 1950 plotted in the same format as used in Figure 2. Fig: 5. Comparison between the polarity of the interplanetary magnetic field inferred using the method described in the text and as originally classified by Svalgaard (1972b).

Fig. 6. Typical changes of the characteristics of the magnetic variations at Thule and at Godhavn as response to the passage of an interplanetary magnetic sector boundary on July 25, 1968. The upper panel shows the 3-hour planetary activity index ap. The next panel gives the azimuthal component of the interplanetary field in solar magnetospheric coordinates. The lower two panels display $\mathrm{Z}$-magnetograms from Thule and H-magnetograms from Godhavn. The variations related to the sector polarity are shared.

Fig. 7. Same format as in Figure 6 , but showing an atypical response at Godhavn as discussed in the text.

Fig. 8. Diurnal variation of the horizontal component, $H$, at Godhavn on internationally quiet days during 1965-69. 
Fig. 9. Diurnal variation of the coefficients ( $a$ and $b$ ) of a fit $\mathrm{H}=\mathrm{H}_{\mathrm{O}}+\mathrm{a} \cdot \mathrm{BY}+\mathrm{b} \cdot \mathrm{BZ}$ of the horizontal component $\mathrm{H}$ at Godhavn to the EastWest component, BY, and the North-South' component, BZ, of the interplanetary magnetic field.

Fig. 10. Comparison between the observed values of $H$ at Godhavn and the values computed from $\mathrm{H}=\mathrm{H}_{\mathrm{O}}+\mathrm{a} \cdot \mathrm{BY}+\mathrm{b} \cdot \mathrm{BZ}$ for four hourly intervals as indicated at the left side of each curve. The figure shows the values for each day during June 1968 for which interplanetary data was available. 


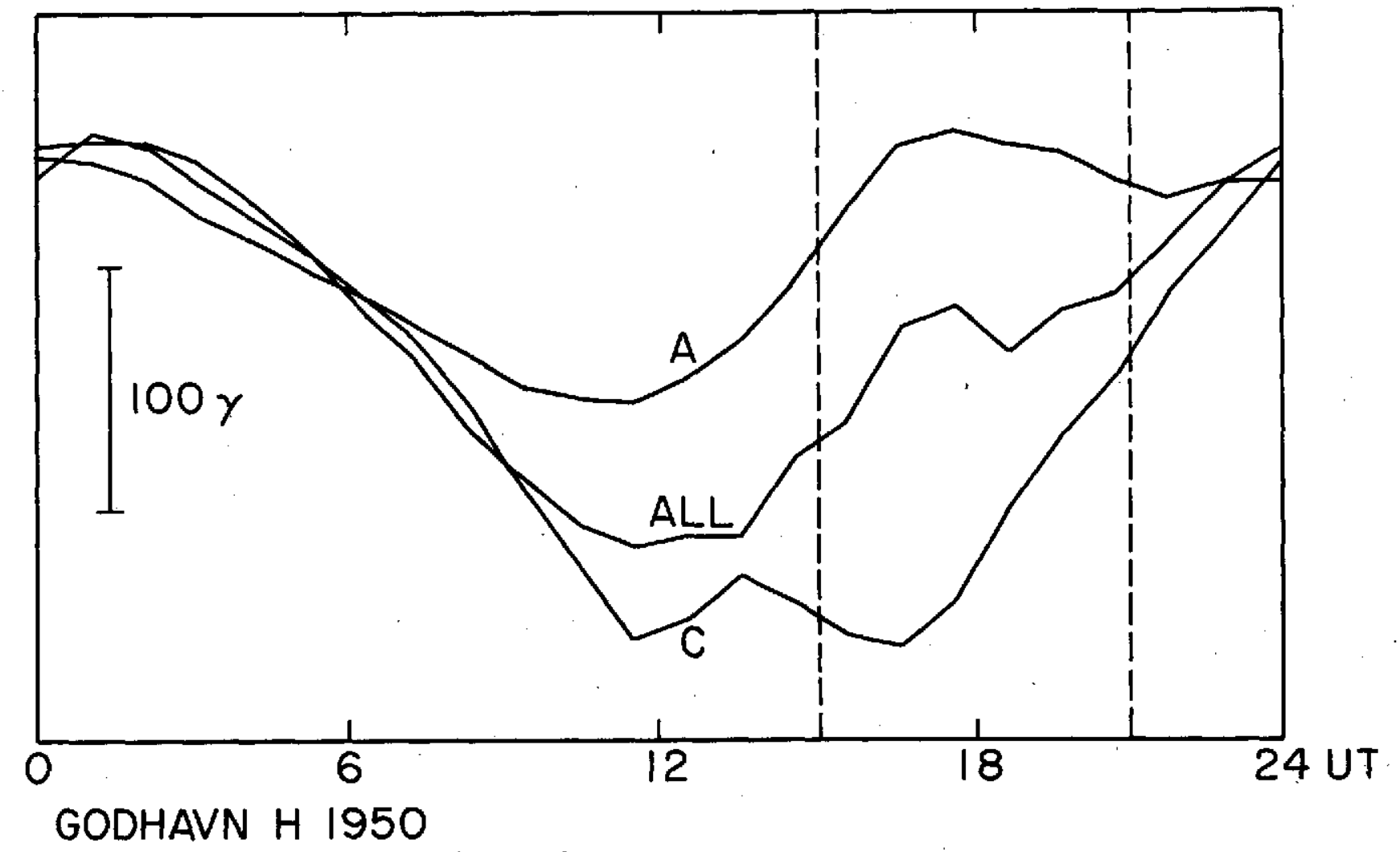

Figure 1 


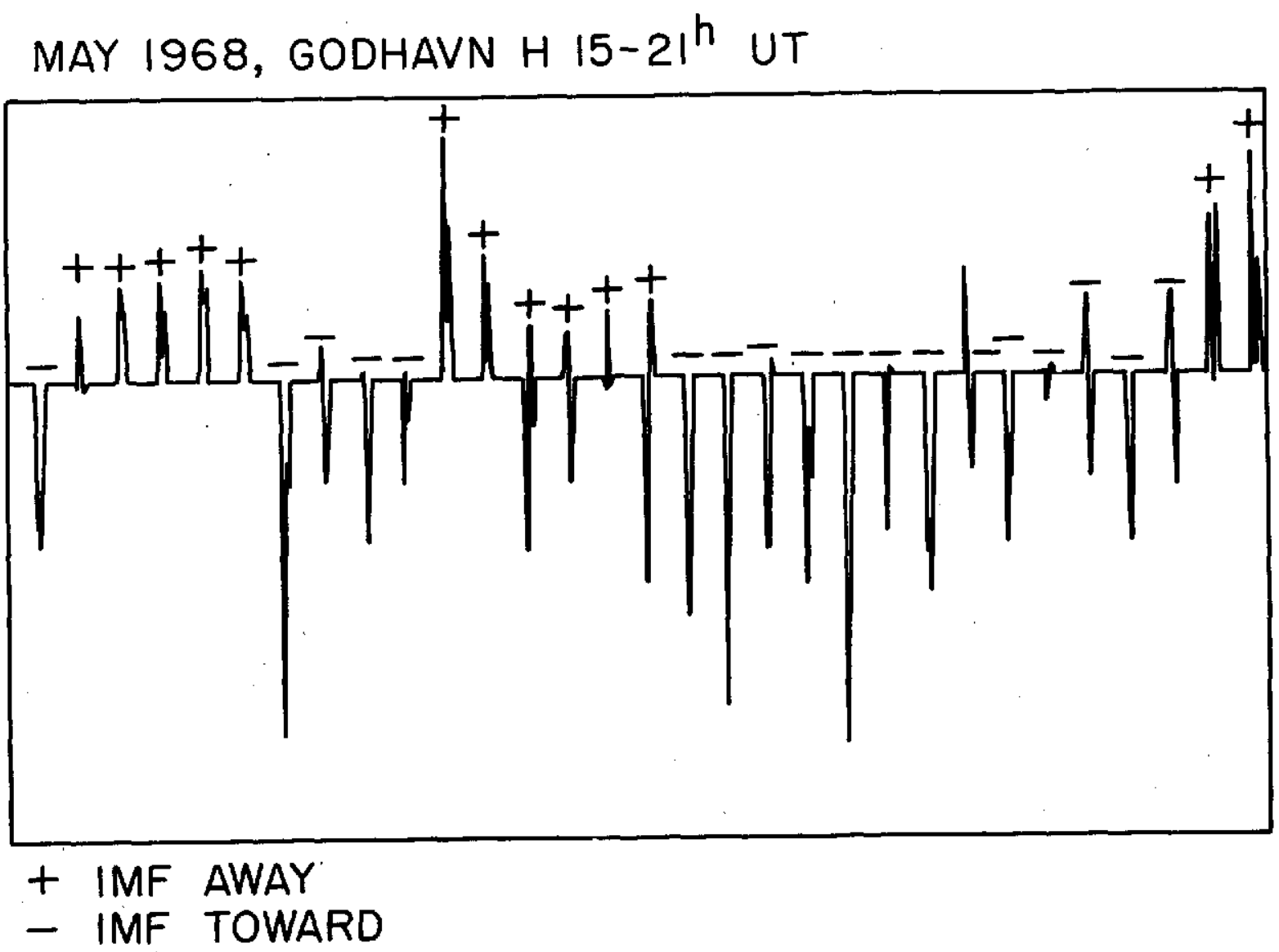

Figure 2 


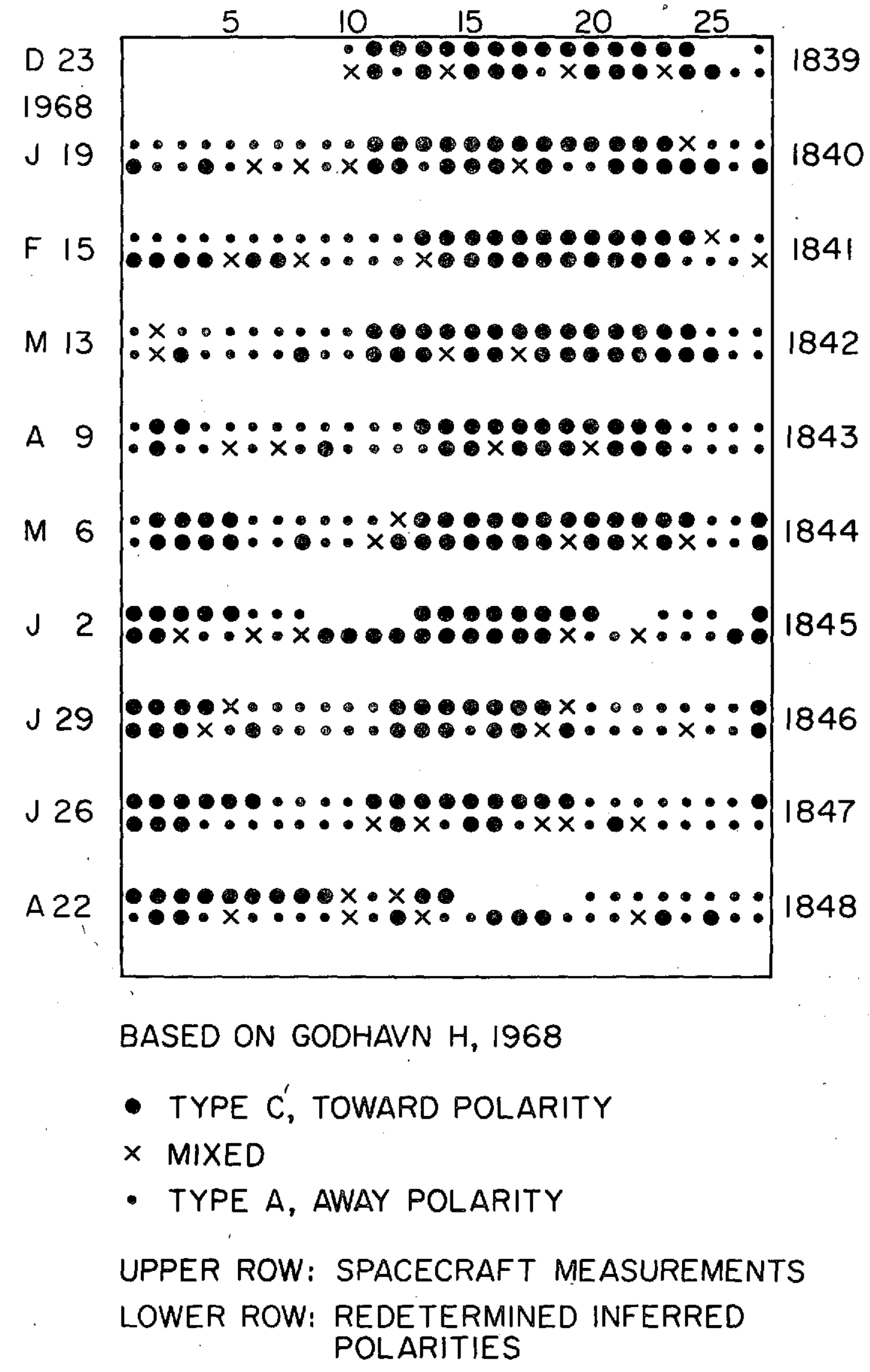

Figure 3 
APRIL 1950, GODHAVN H $15-21^{\text {h }}$ UT

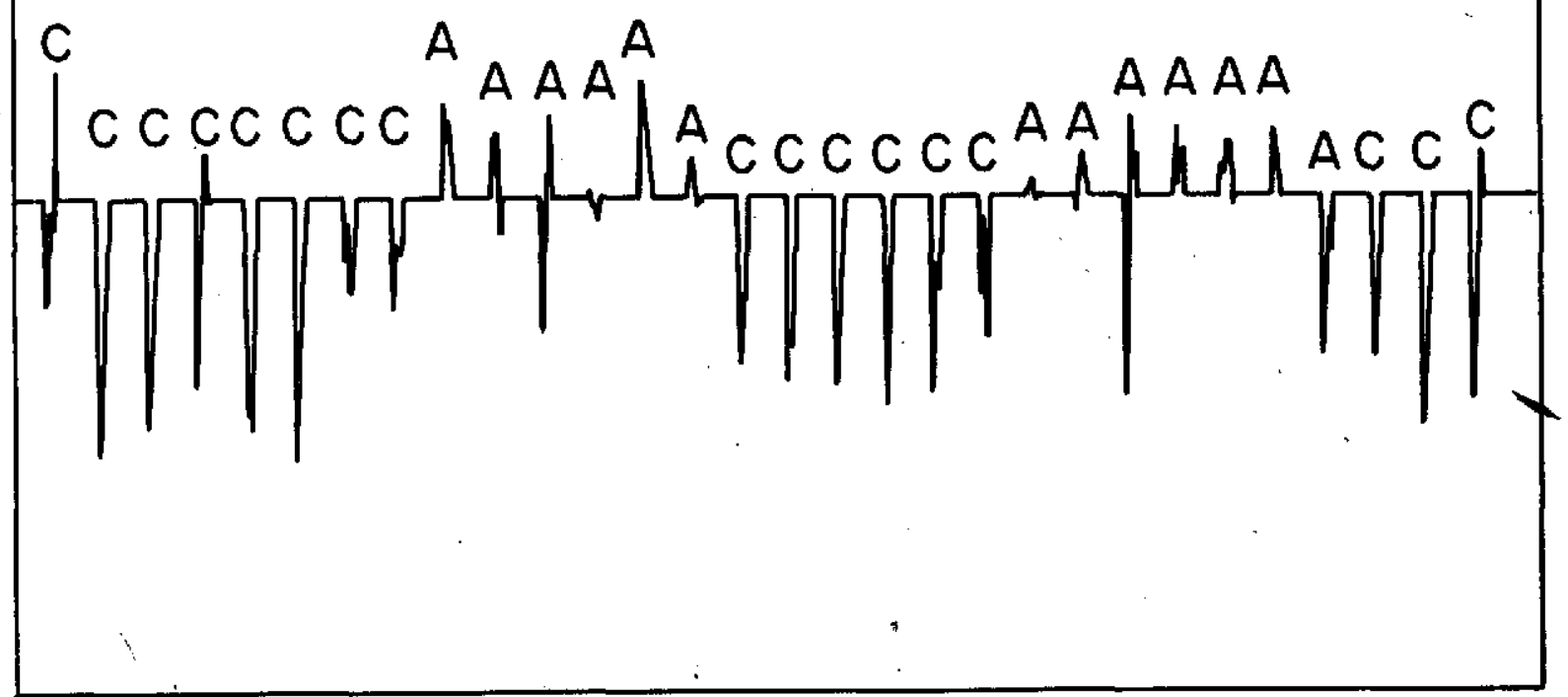

A INFERRED IMF AWAY

C INFERRED IMF TOWARD

Figure 4 


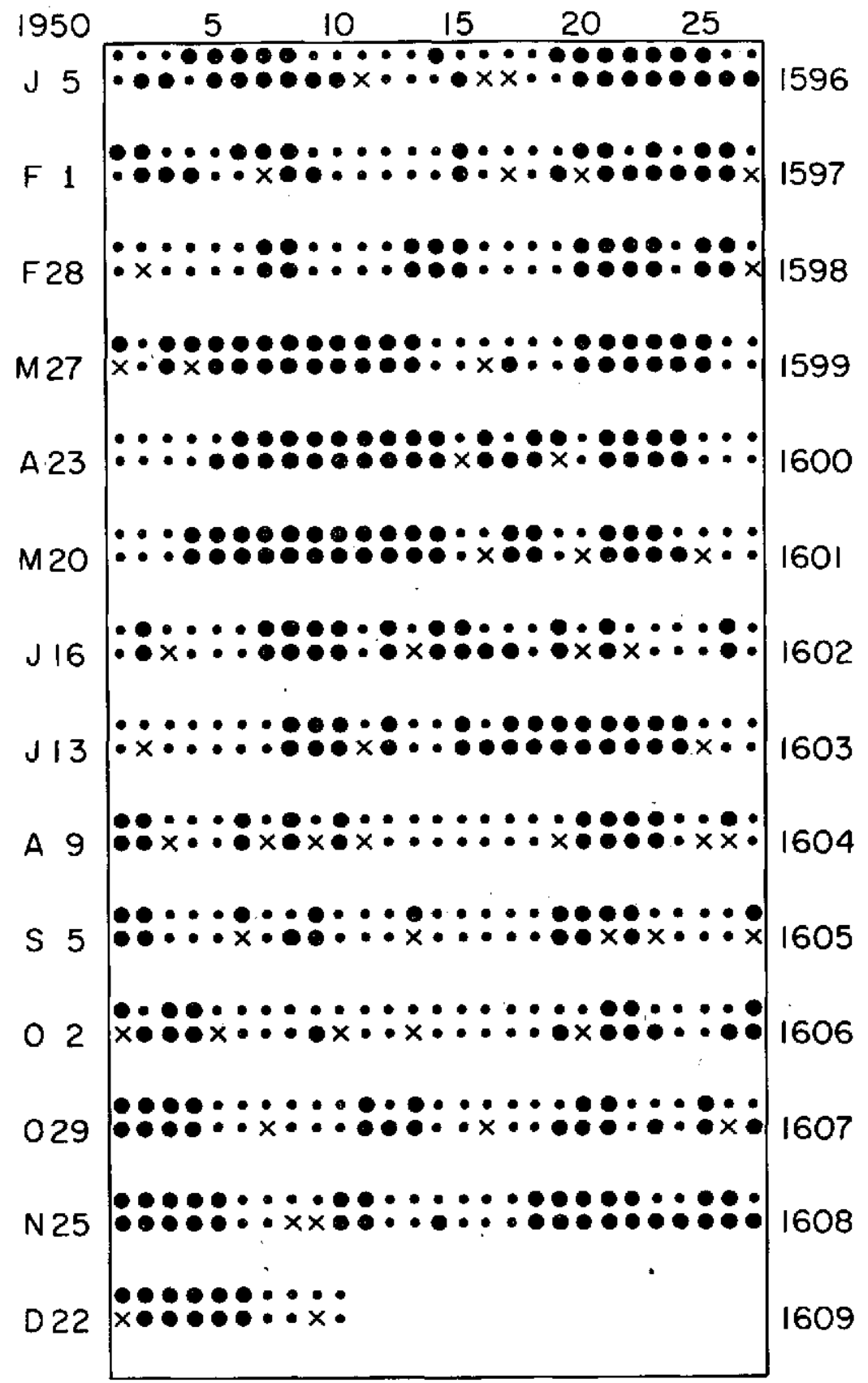

BASED ON GODHAVN H, 1950

- TYPE C, INFERRED TOWARD POLARITY

$\times$ MIXED

- TYPE A, INFERRED AWAY POLARITY

UPPER ROW: ORIGINAL VISUAL ESTIMATES

LOWER ROW: REDETERMINED POLARITIES 

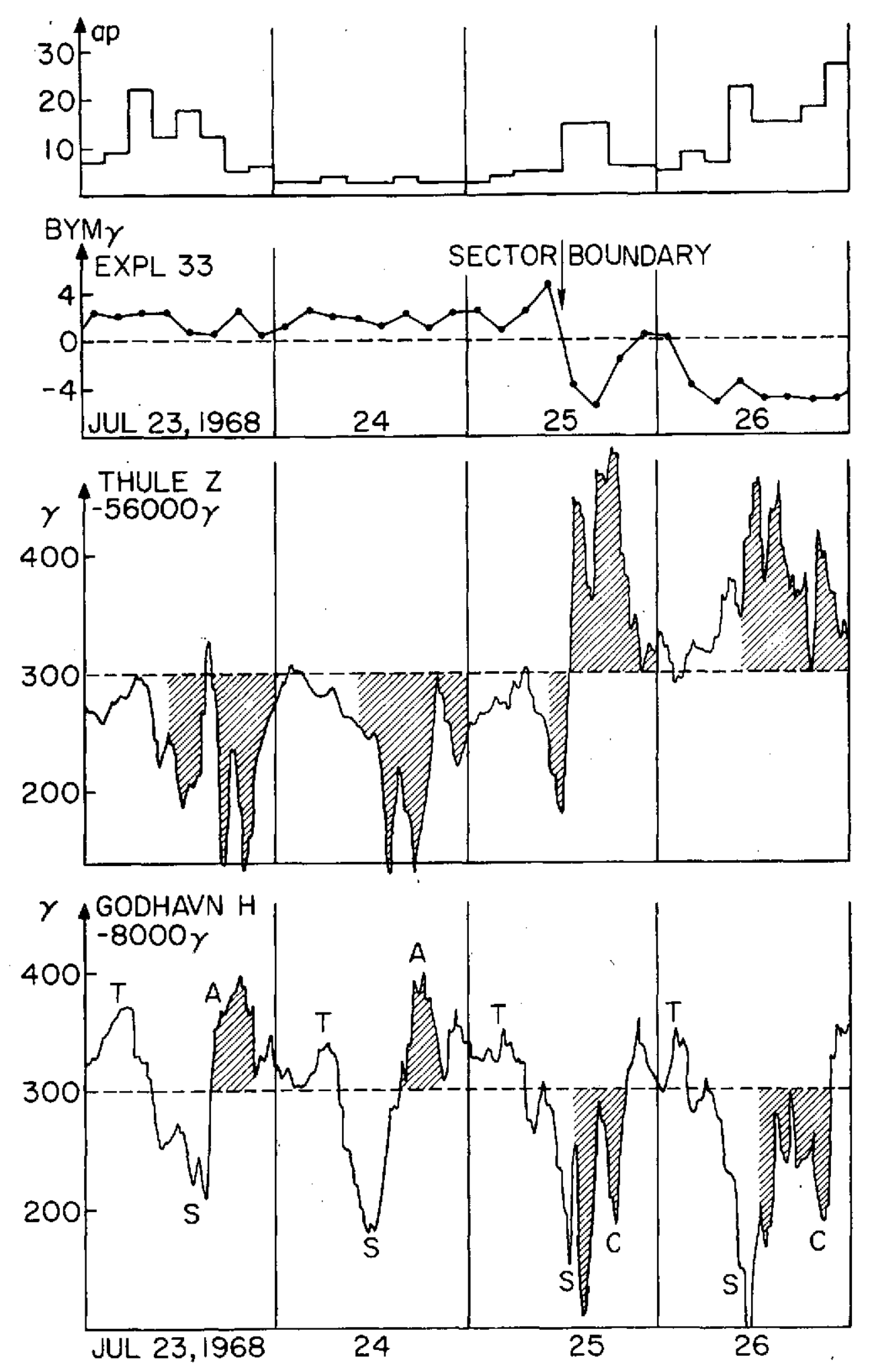

Figure 6 

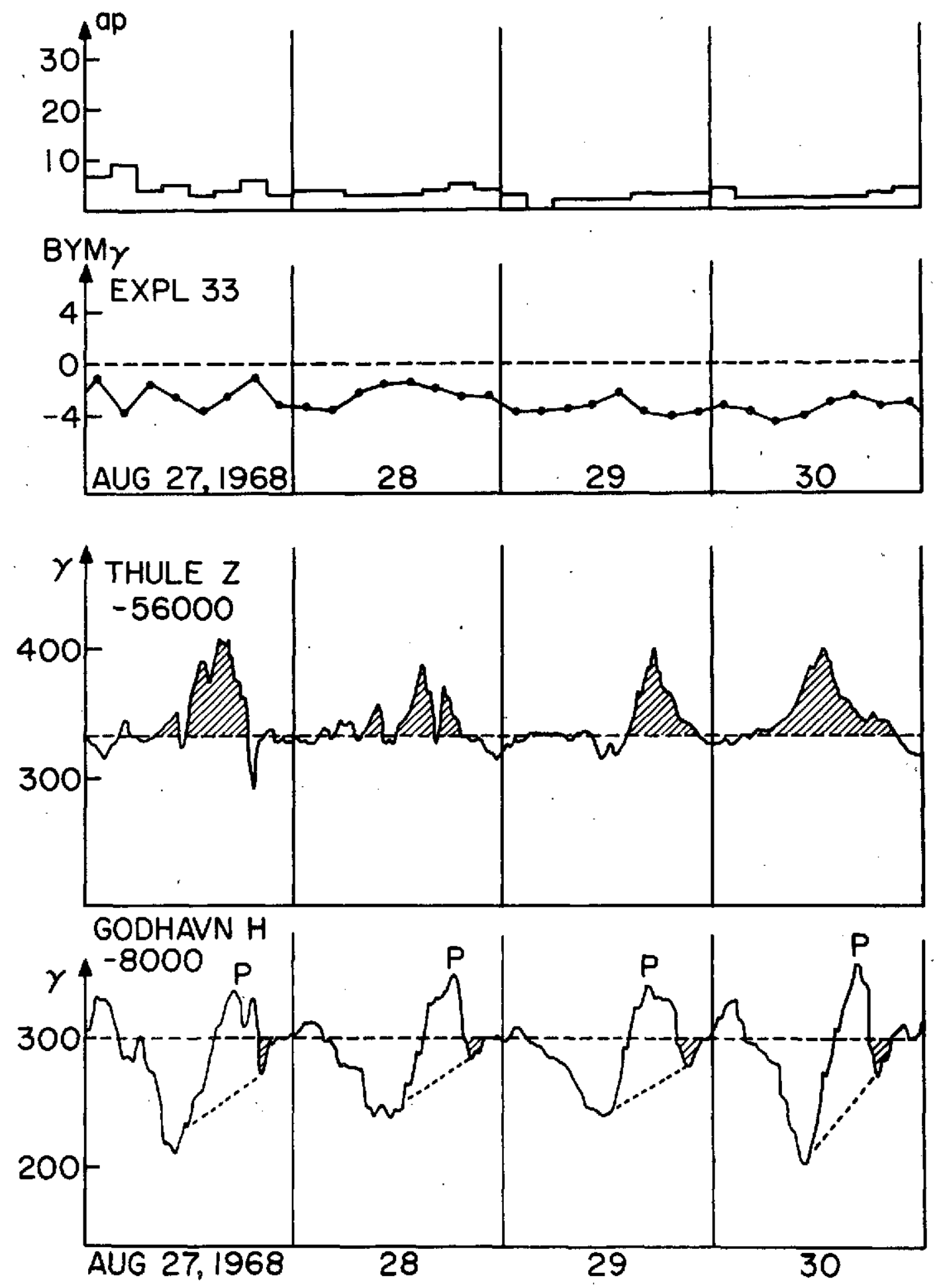

Figure 7 


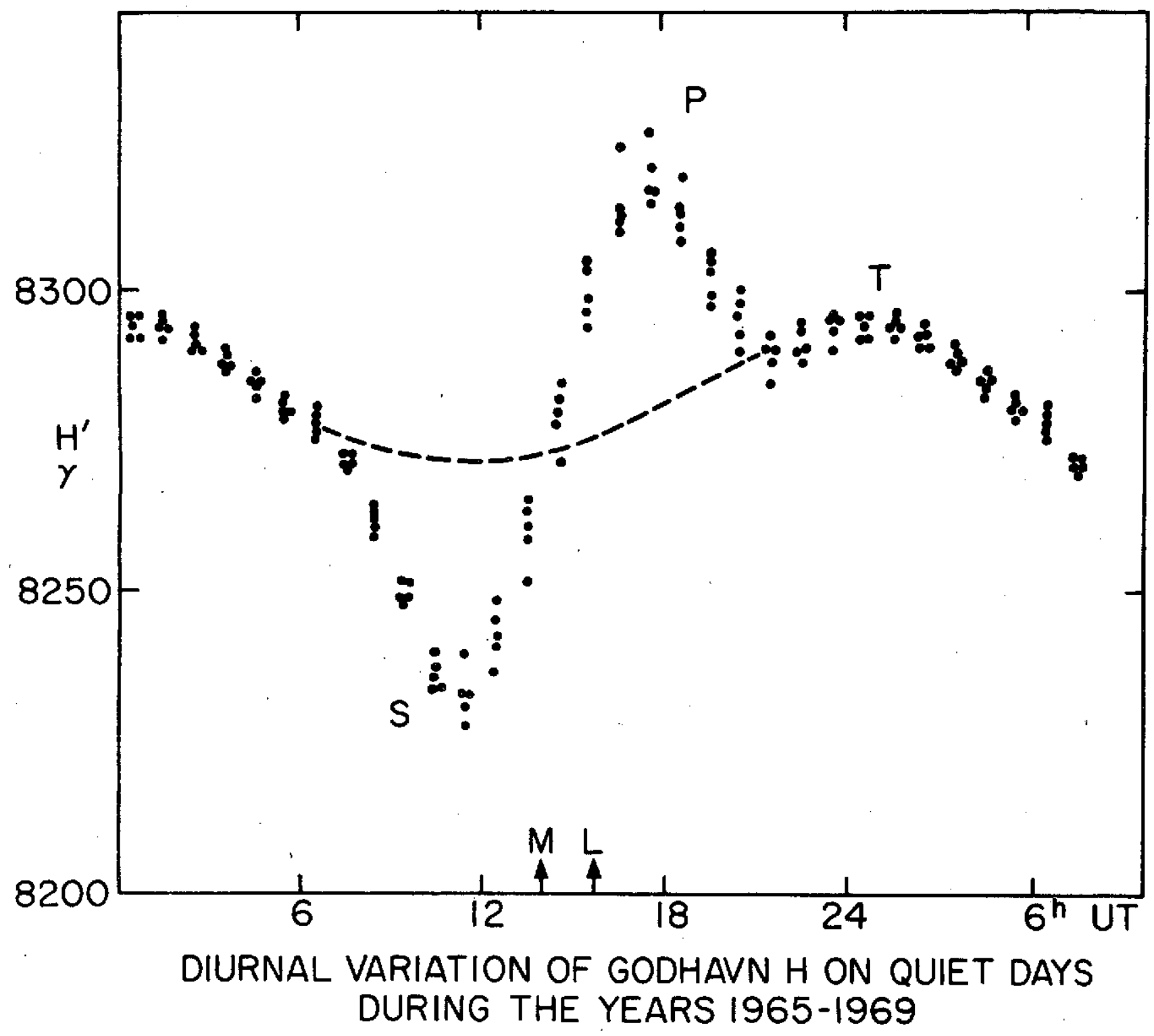

Figure 8 

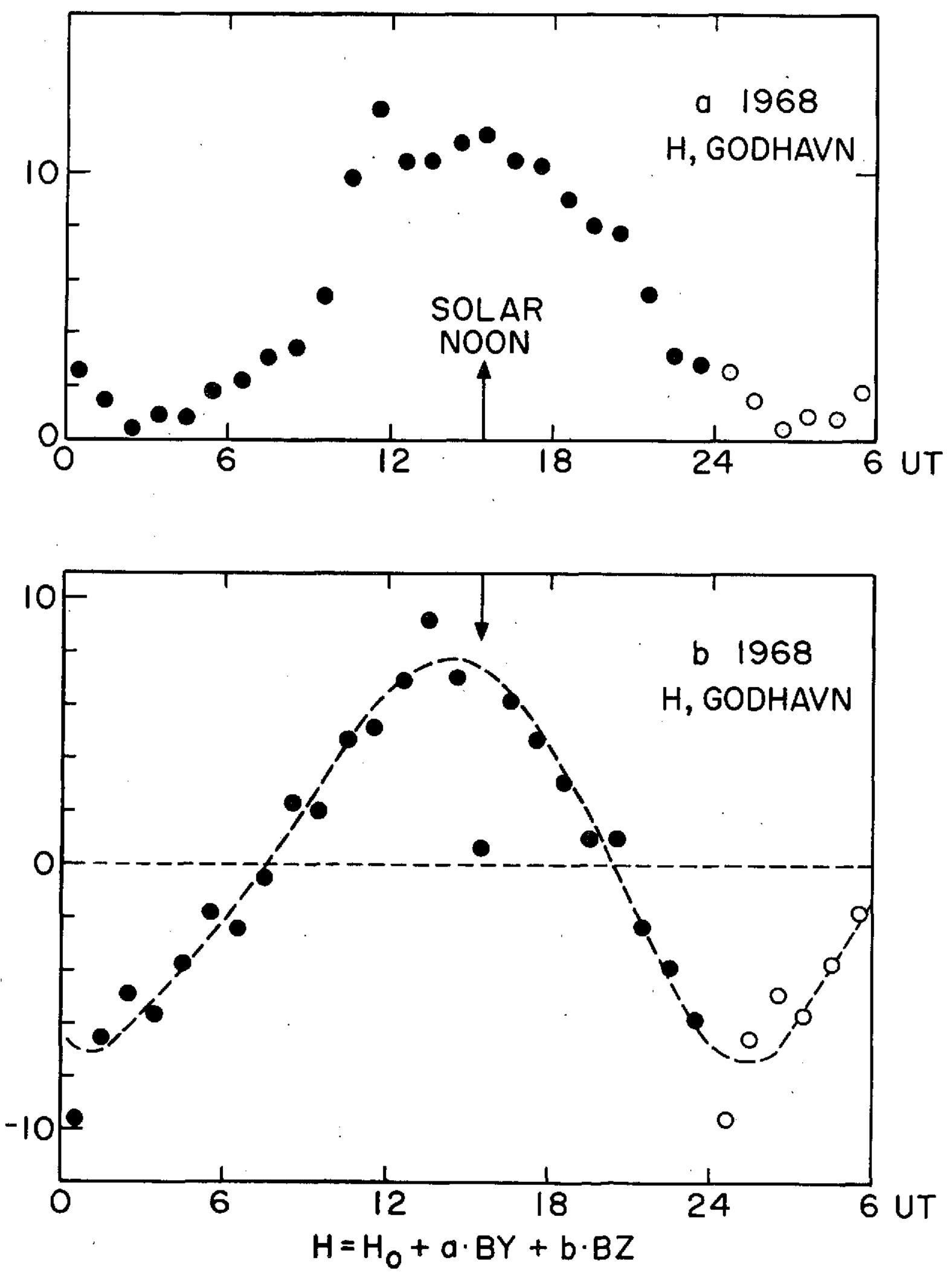

Figure 9 


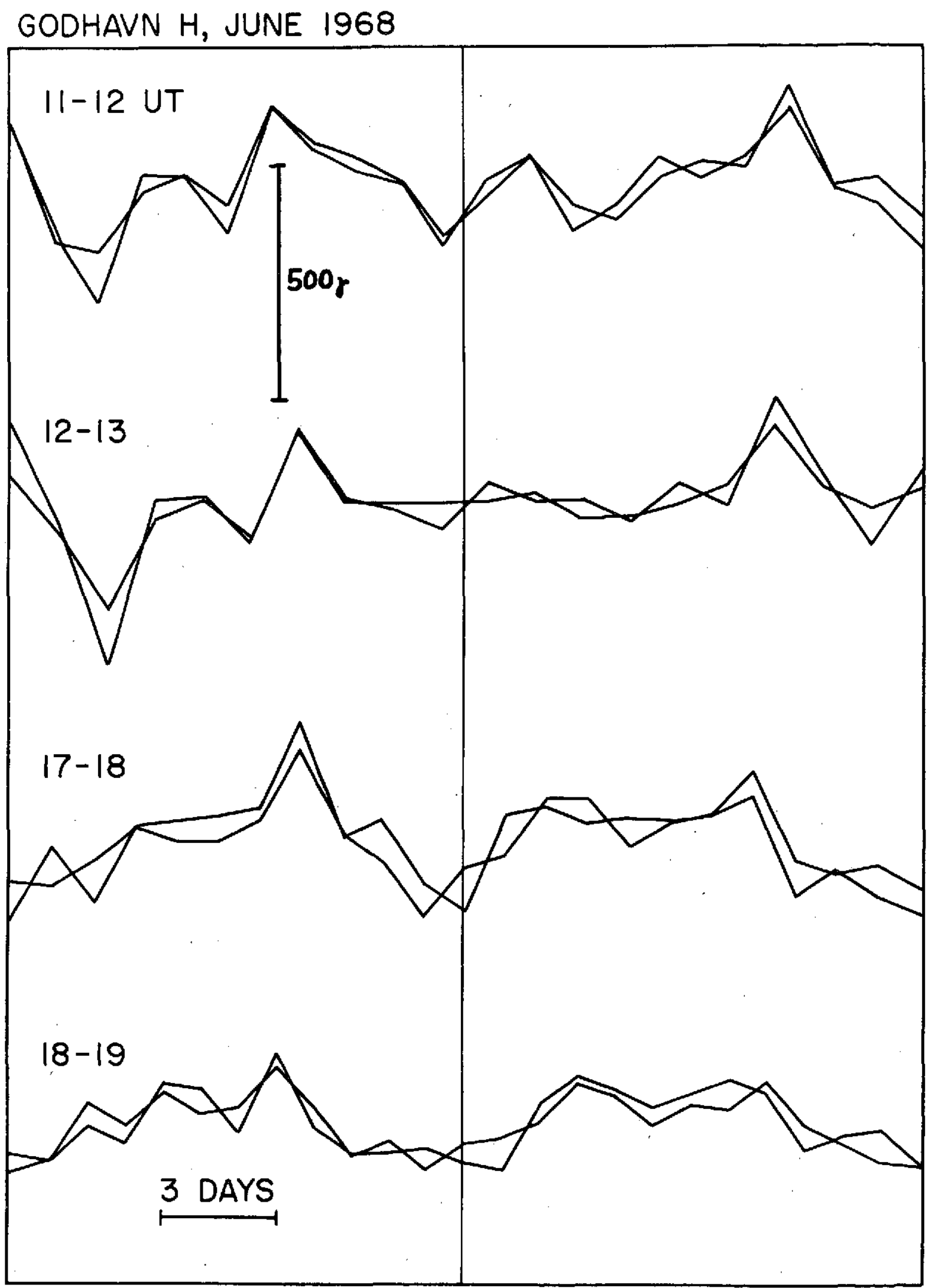

Figure 10 